\title{
Clinical supervision and support for bridging programme students in the greater Durban area
}

\author{
P Pillay \\ School of Nursing University of KwaZulu Natal
}

NG Mtshali

Professor : School of Nursing University of KwaZulu Natal

\section{Key Words:}

Clinical supervision; Student; Clinical supervisor; Bridging Programme

\section{Abstract: Curationis 31(4): 46-56}

Reviewed literature revealed that clinical supervision is a conceptually sound learning model, which, unfortunately, is flawed by problems of implementation. Some of the more glaring problems include limited emphasis upon problem-solving, lack of clear expectations for student performance, inadequate feedback to students, inappropriate role models in clinical settings and inadequately prepared clinical teachers.

The purpose of the study was to explore and describe the nature of clinical supervision and support provided to bridging programme students in the clinical settings. Participants were drawn from three nursing colleges and 122 participants returned questionnaires. College $1: 26,2 \%(n=32)$, College $2: 15,6 \%(n=19)$ and the majority, 58, $2 \%(n=71)$ were from College 3 . The participants were second year students in the Bridging Programme.

Purposive sampling was used for the selection of the hospitals. The researcher purposively selected those hospitals offering the Bridging Programme. The students were randomly sampled. According to Burns and Grove (2001), simple random sampling is the most basic and most effective of the probably sampling methods. Data was collected by means of a questionnaire and a critical incident report. The questionnaire used in this study was adapted from the Manchester Clinical Supervision Instrument. The findings revealed that clinical supervision contributes positively to the academic, professional and personal development of students. Although there was support for clinical supervision by the nursing staff, time for clinical supervision was the main problem. Clinical supervision was viewed as time consuming. Clinical learning emerged as secondary to ward routine. The students functioned as part of the workforce and missed out on some important learning opportunities. Results also showed that some clinical supervisors were not adequately prepared for their roles and responsibilities; as a result there was no significant relationship between clinical supervision sessions and the acquisition of knowledge. The critical incidence revealed positive and negative experiences regarding clinical supervision and the support provided by clinical supervisors and clinical staff.

There is a need for clear policies regarding clinical supervision, a structured and well monitored process of clinical supervision, building the capacity of clinical supervisors, and addressing the issues of use of bridging programme students as part of the workforce.

\author{
Correspondence address: \\ Padmini Pillay \\ 5th Floor \\ Desmond Clarence Building \\ UKZN
}

Tel : (031) 260-3045

Cell : 0826530179

Email: Pillayp29@ukzn.ac.za 


\section{Introduction and Background}

The concept of clinical supervision can be traced as far back as the time of Florence Nightingale, where experienced nurses provided guidance to less experienced nurses in their clinical work (Winstanley \& White, 2003:3). According to Benoliel (1988:340), students need (a) a sense of being cared for during the process of learming to care for others, (b) they need to feel that they are receiving support and guidance whilst dealing with clinical experiences in which they perceive themselves to be failures or incompetent at. Some of these themes emerged in the study by Smith (2000:5), which emphasised the need for psychosocial support over and above academic support.

According to Tiwari, Lam, Yuen, Chan, Fung and Chan (2005:299) clinical learning plays a crucial role in nursing education programmes. Not only does it provide opportunities for students to apply the theory learned in the classroom to the real world of clinical nursing, it is also a socialization process through which students are inducted into the practices, expectations and real-life work environment of the nursing profession. . Proctor (2001) regards clinical supervision as having three aspects: normative, formative and restorative.

Clark, Jamieson, Launer, Trompetas, Whiteman and Williamson (2006:106) categorize clinical supervision into educational supervision, remedial supervision and mentoring. Educational supervision is organized clinical supervision taking place in the context of a recognised training programme. As well as providing opportunities for support and development, the supervisor also has to assess the supervisee's performance and report on this to others so that they can judge if the person makes the grade for a particular qualification. According to Clark et al. (2006:106) within educational supervision there is generally a clear contract regarding who is reporting to whom, about what, and why. These authors state that in terms of Proctor's analysis, the emphasis within educational supervision is generally on the formative aspect of the work. Each of these aspects according to Clark et al (2006:106) may come to the fore or remain in the background in clinical supervision, according to the circumstances.

Clinical learning is defined by Henderson (1995) as the mode that provides students with the opportunity to translate theoretical knowledge into the learning of a variety of skills required to give patient-centred care. It facilitates correlation of theory with practice in the cognitive, affective and psychomotor domains in the clinical setting for the students to reach acceptable levels of competence in these areas. Mthembu (2003) states that clinical learning is described as being at the heart of professional education, as it provides a student with the opportunity to consolidate knowledge, socialize into professional roles and acquire professional values. Yet most professionals still seem to regard it as having connotations of performance monitoring and management. They think it means having someone looking over your shoulder instead of looking after you.

Learning in clinical settings is an important part of the curriculum and accounts for approximately $50 \%$ of the pre-qualifying nursing programme (Humphreys, Gidman \& Andrews, 2000:311). Supporting students to leam in clinical settings is an important function for both educators and practitioners, yet there is little consensus in the literature as to what constitutes appropriate support of clinical learning (Andrews \& Roberts, 2003:474). The quality of clinical learning of students, according to Andrews \& Roberts $(2003: 474)$ is influenced by a variety of factors including the learning culture and by more practical things such as how busy the area is and the level of patient need. Furthermore, the intensity of support afforded to students is influenced by the nature and complexity of the ward environment. More importantly, students view learning and patient care as two quite separate activities. Although clinical education is essential and valuable, it is not without difficulties and constraints as is stated by Tiwari, et al. (2005:299). To these authors, the clinical environment is unpredictable, constantly changing, and potentially confusing for students, hence promoting optimal learning in such an environment is challenging. Moeller (1984:205) also claims that the clinical instructor who supervises the student during the 'hands on' practice often bears the burden of being the final gatekeeper to the profession.

The research conducted by Tiwari et al. (2005:299) revealed that students' learning during the clinical practice is, to a large extent, affected by their perceptions of the assessment tasks. They learn for the examinations, not for the sake of learning. As a result, they adopt a surface approach to learning and focus on preparing for the assessment of tasks to the detriment of their learning. These authors refer to this as a negative backwash effect on learning. These authors recommend research studies that will explore perceptions about student learning in the clinical environment and the relationship between assessment and student learning. This proposed research intends to describe the perceptions the pupil nursing auxiliaries have about their clinical learning, how they learn in the clinical settings, and the influence of assessment on their clinical learning Mogan and Knox (1997:331), as well as Irby (2004:808), indicated that there are concerns about clinical teachers as role models in clinical settings. According to these authors, many clinical instructors and clinical staff fail to serve as exemplary role models in a number of ways. Henderson (1995:121) views role modelling as a powerful teaching technique. According to Henderson, modelling involves demonstrating exemplary professional characteristics. These include the non-cognitive dimensions of professional practice such as showing genuine concern for patients, recognizing one's own limitations, showing respect for others, taking responsibility, and not appearing arrogant. If the attending professionals treat patients with respect and genuine concern, students will do the same. The reverse is also true.

Jinks and Paterman (1998:12) found that the students felt that they had insufficienient clinical skills upon completion of pre-registration programme. According to Bjork (1995:6), Elkan \& Robinson, (1993:295), the production of inadequately competent graduates is attributed to existing tension between education and service with regard to the value of practical skills in nursing. The priorities of these two (education and service) are not the same and the planning of teaching and 
learning is dominated by education institutions with minimal involvement of service.

According to Quinn (2000:417) qualified staff is a key factor in influencing the learning environment of student nurses during the clinical practice, the role of the unit manager being particularly important.

\section{Problem Statement}

The study focused on bridging programme students because of their dual status as students and employees. According to Zulu (2004:22) the learning needs of students of this nature are in most cases neglected, because they are regarded as part of the workforce. They do not get adequate clinical supervision because it is assumed they know most of the work. Some units rely on the bridging programme students because they are a better kind of student; they are familiar with the routine and therefore require less assistance and attention from the ward staff. Taking these students away from their daily activities for clinical supervision sessions poses a challenge because this means that the unit is minus a staff member. Work tends to be a priority as opposed to the learning needs of students. Lita,Alberts, Van Dyk \&Small(2002:30) found that the workload and shortage of personnel limited the opportunities for proper teaching and guiding of students.

In a study of perceptions of the clinical competences of newly registered nurses done by Mocti, Van Niekerk \& Van Velden (2004:72) it was also found that a shortage of staff, equipment and supplies negatively affects the competency of students. Furthermore, when afforded an opportunity to attend a clinical supervision session together with traditional students, they are given less attention than the traditional students. It is assumed that bridging programme students are familiar with the ward procedures and most of what takes place in clinical settings. Ward staff tend to ignore that the bridging programme students are in the process of being prepared for a higher level in their career and for responsibilities different from those of an enrolled nurse. It is also acknowledged that some of the bridging programme students have, over the years of their practice as enrolled nurses, developed unacceptable practices. They have to be assisted by clinical supervisors to relinquish these practices.

According to Lipinge and Venter (2003:10) negative experiences have also been reported by students in the clinical environment. This negative experience include for example (a) the expectations of students not being met, as the staff are not aware of the students' learning objectives (b) frustration experienced during daily practice due to poor integration of theory and practice and (c) the lack of tutorial support and guidance by lecturers.

Interpersonal relationships between the ward sister and students are a problem. Students were called names and used as scapegoats for wrong doings. Because of these negative attitudes the students would have negative clinical learning experiences.

Lack of effective communication between college tutors and ward staff also contributed to negative experiences of students.

\section{Research objectives}

1. To identify and describe preconditions to be taken into consideration in a bridging programme for clinical supervision to be effective.

2. To identify the teaching/ learning processes during clinical supervision in a bridging programme.

3. To determine and describe the type of support provided to bridging programme students when they encounter a critical incident in the clinical setting.

\section{Research Questions}

1. What are the preconditions that should be taken into consideration in a bridging programme for clinical supervision to be effective?

2. What are the teaching/learning processes for clinical supervision in a bridging programme?

3. What support should be provided to bridging programme students when they encounter a critical incident in the clinical setting?

\section{Operational Definition of Terms}

Clinical supervision is a process through which the clinical supervisor facilitates the process of growth of a novice (the learner) towards becoming a competent professional. This process has three core functions namely: an educative function which enables the development of skills, understanding and abilities, by reflecting on, and exploring the person's work-based learning experience; a supportive function providing support to enable the person to deal with what has happened and move on, and a managerial function which includes the provision of quality control. (Hyrkas 2002)

Student- The term student will be used interchangeably with that of learner in this study. This term refers to the second year bridging programme students who are registered at an institution being used in this study with the aim of qualifying as registered nurses. (SANC Regulation No. R683 of April 14, 1989)

Clinical supervisor refers to a registered nurse with practical and professional experience and with theoretical knowledge who is employed in a teaching hospital in order to teach student nurses in clinical settings. (Hyrkas2002)

Bridging programme refers to a two year Diploma in General Nursing (often referred to as the bridging programme) leading to registration as a general or psychiatric nurse in accordance with the SANC Regulation No. R683 of April 14, 1989 as amended.

\section{Conceptual framework (Figure 1)}

The conceptual framework is modified from the model which was developed by Hyrkas (2002:50). This conceptual framework has three important dimensions; antecedent or preconditions, the core of clinical supervision and outcomes of clinical supervision. Antecedent conditions are those conditions which should be in place before the actual supervision process. The concrete arrangements and resources such as money, human resource, time and place are considered important preconditions for clinical supervision. Lack of resources seems to be the biggest threat to the occurrence of clinical supervision. In the context of this study all resources for clinical supervision to take place should be 
provided. This will include appointing suitable qualified clinical supervisors, providing a set schedule ensuring that clinical supervision consistently takes place and to ensure that there is communication between the academic institution and the clinical settings. The contract between clinical supervisor and learner is the crux of clinical supervision. There should be an agreement between supervisor and student. The agreement is described as a contract where practical arrangements such as the duration of clinical supervision and the rules are discussed. The agreement should detail the roles, responsibilities and expectations during the teaching learning process. The clinical environment should have appropriate learning experiences that will facilitate the development of required competences .Certain specific personal characteristics of the students are important for effective clinical supervision. This can be summarised in terms of demographics, motivation to learn, self- confidence and willingness to acquire feedback. The core of clinical supervision includes important issues such as clearly stated goals of each clinical supervision session, a teachinglearning process that facilitates the achievement of expected outcome, a relationship between the supervisor and the student that promotes learning, and availability of time for clinical supervision. The time aspect has been considered important in the sense that the time used for clinical supervision should be protected from other duties. The goals are described as individually emphasised, based on the student's specific needs but also coherent with organization or unit activities (Hyrkas, 2002).The teaching - learning process is described as having practice-oriented learning experiences comprised of everyday learning. The supervisory relationship, especially the interaction between supervisor and supervisee, are seen as the core elements of clinical supervision. The qualities related to the relationship and interaction have been described with several attributes such as supporting, facilitating and encouraging. Outcomes are related to development of the learner academically (knowledge, skills, values), professionally and personally.

The benefiting restorative and supportive outcomes for an individual supervisee have been described in terms of decreased stress, improved self -

confidence and a high self - esteem.

\section{Research design and method}

A quantitative and qualitative design was used in this study. Three colleges were used as research settings in this study (2 private and 1 public). These were the only three hospitals that offered the Bridging Programme. The researcher included students from the private institution because these students come from different cultural race groups. The population was made up of students enrolled in their second year in the Bridging programme. There is a chance that some of them may be supervised by a supervisor that is not from the same cultural groups. Second year students were thought to be more appropriate in this study because of the period they had already spent in the programme. The total population of the three settings is 325 students. The target sample was 150 students. 170 questionnaires were sent out to allow for attrition. The participants were randomly sampled and 122 returned their questionnaires. Of the 122 participants in the study, $26.2 \%(n=32)$ were from College $1,15.6 \%(n=19)$ were from College 2, and the majority, 58.2\% $(n=71)$ were from College 3 .

Data was collected through a selfdeveloped instrument which was based on the Manchester Clinical Supervision Instrument by Winstanley and White (2002) According to Winstanley and White(2002) the Manchester Clinical Supervision Instrument is the only internationally validated research instrument to measure clinical supervision. A critical incident was also used to gain more information about the support provided to students.

The critical incident results were based on 25 participants. The low response to this critical incident question was because it took longer to answer than the other questionnaire, and some students said that the questions intruded upon the confidentiality of student and clinical supervisor.

The participants reflected on this situation, detailing the situation, the support system that was approached, the process by which the situation was dealt with, and the evaluation of the support that was offered and recommendations for the future. Content validity was conducted by subjecting the instruments to the scrutiny of experts in nursing education and in research, and suggested corrections were made appropriately. A test-retest was conducted to establish the reliability of the instrument. The questionnaire was administered to 10 students and then readministered after a two week interval. The answers were checked and to see that they were similar on both the occasions. Scores on the repeated testing were compared and the comparison was expressed by a Pearson r. correlation coefficient. The correlation yielded was 0.96 , which supports the idea that the instrument has the attribute of stability. Permission to conduct the study was sought from the authorities and the participants completed consent forms after the process of explaining the research and their rights. The names of the three colleges are not used as this was part of the arrangement before data collection. The colleges are referred to as College 1, College 2, and College 3 .

\section{Data analysis}

Data will be qualitatively and quantitatively analysed.

Data was captured and analysed in SPSS version 11.5 (Chicago, Ill). Frequency distributions were used to analyse the Section A(demographic data, and Clinical Supervision antecedents) and Post hoc Kruskal-Wallis Multiple Comparison Z value tests were performed in NCSS (Hintze, J. 2001) to analyse section B (clinical Supervision Scale) Since the dependant variable was significantly non - normally distributed, a non - parametric equivalent of one-way ANOVA (ie, the Kruskal-Wallis test) was used to compare values between the groups. If the overall test was statistically significant, post hoc $\mathrm{z}$ tests with a Bonferroni adjustment were used to determine which groups were indeed statistically significantly different from each other. The questionnaire contained 42 individual statements on clinical supervision. These were graded on a Likert scale, and treated quantitatively. The distribution of these responses was highly skewed, thus nonparametric methods were used for description and analysis of the statements. Comparison of the responses to the clinical supervision statements amongst the three colleges was achieved by nonparametric Kruskal-Wallis testing, with post-hoc Multiple Comparison $\mathrm{Z}$ value tests. Responses were scored (scoring was reversed for the negatively 
Figure 2: Ages of students versus the ages of clinical supervisors

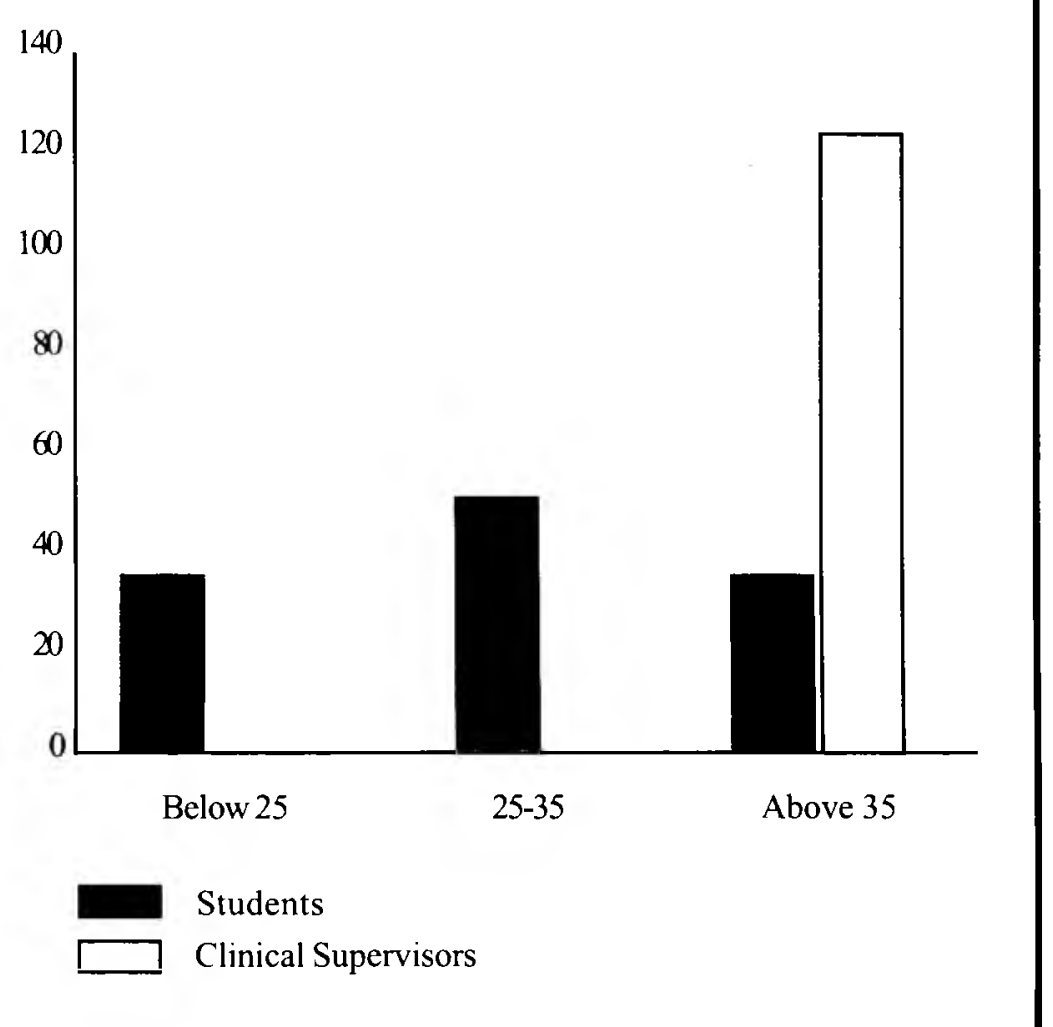

phrased statements) and summed for each individual, and total scores compared amongst the three hospitals using the same methods as above. Critical incidents and support given were categorized and compared amongst the three hospitals.

\section{Results}

The results are presented according to the major concepts in the conceptual framework that was used in this study; antecedent conditions, core of clinical supervision and outcomes of clinical supervision.

\section{Antecedents of Clinical Supervision}

Only $2 \%(2)$ of the students were younger than 25 years, $58 \%$ (51) were aged between 25 and 40 and $40 \%$ (35) were older than 40 years. The clinical supervisors, on the other hand, were all more than 40 years. According to the conceptual framework (Hyrkas, 2000:13) used in this study, the age difference between the student and the clinical supervisor is an important factor to be considered. If the age difference is too large, it might affect the working relationship between the student and the supervisor. The older clinical supervisor supervising a very young student might study, gender is one of the factors affecting clinical supervision. This framework states that differences in demographics may have an influence on how students view clinical supervisors and vice versa. Defensive feelings and dominating authoritative behaviour might be displayed during the working relationships.

$73 \%(89)$ of the clinical supervisors were qualified as nurse educators, and $27 \%$ (33) were not registered as nurse educators. The conceptual framework used in this study supports the idea that a clinical supervisor should be a person with knowledge, expertise and theoretical knowledge at a higher level than that of students. The use of clinical supervisors without a nursing education qualification may be justified, in that their knowledge level may be higher than that of students and they may be more experienced than students.

\section{Clinical supervision antecedents}

Although the respondents stated that there was no formal contract between them and the supervisor they indicated that the first session with the supervisor was used to detail the goals of clinical supervision, the roles and expectations from both parties (the student and the clinical supervisor). In this way there was a verbal contract. $73 \%$ of the respondents had a meeting with the supervisor where what is supposed to be in a formal contract was discussed. $22 \%$ had no formal session where roles According to the framework in this

Figure 3. Contract between Students and Clinical Supervisor

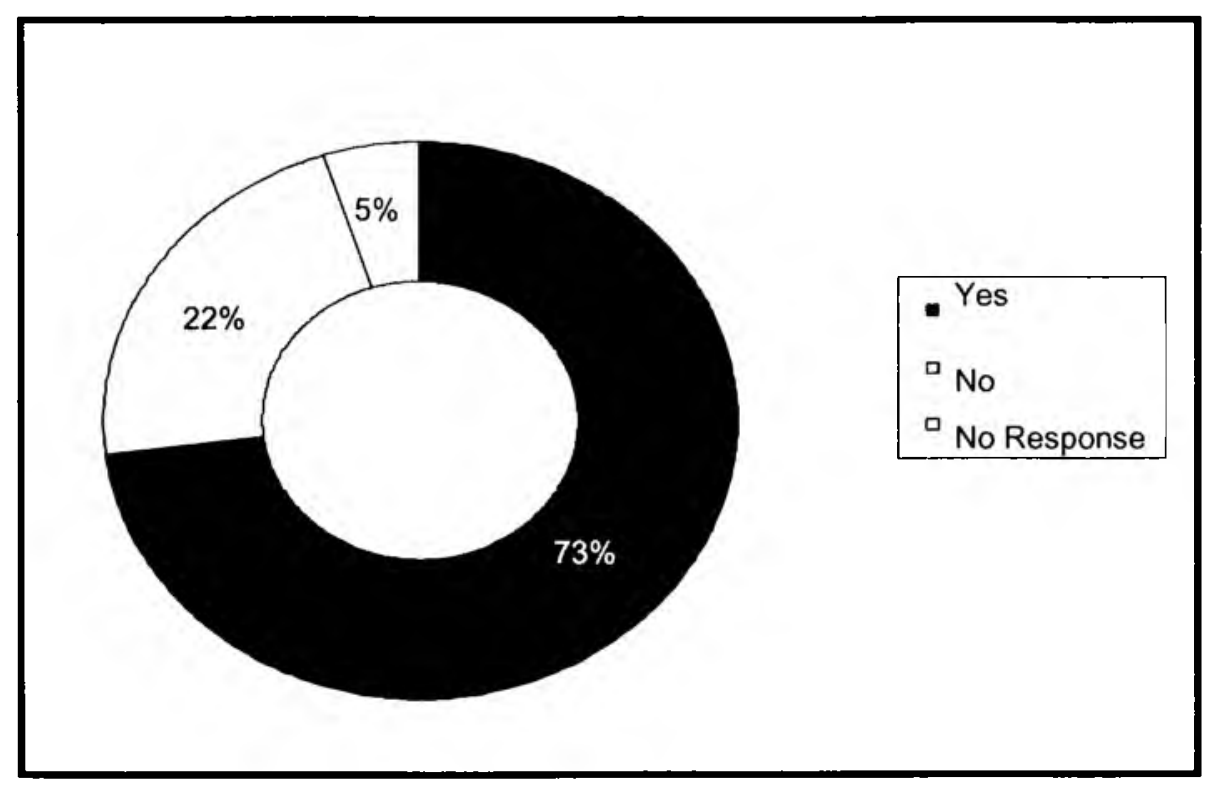


Figure 4: Contents of a Contract

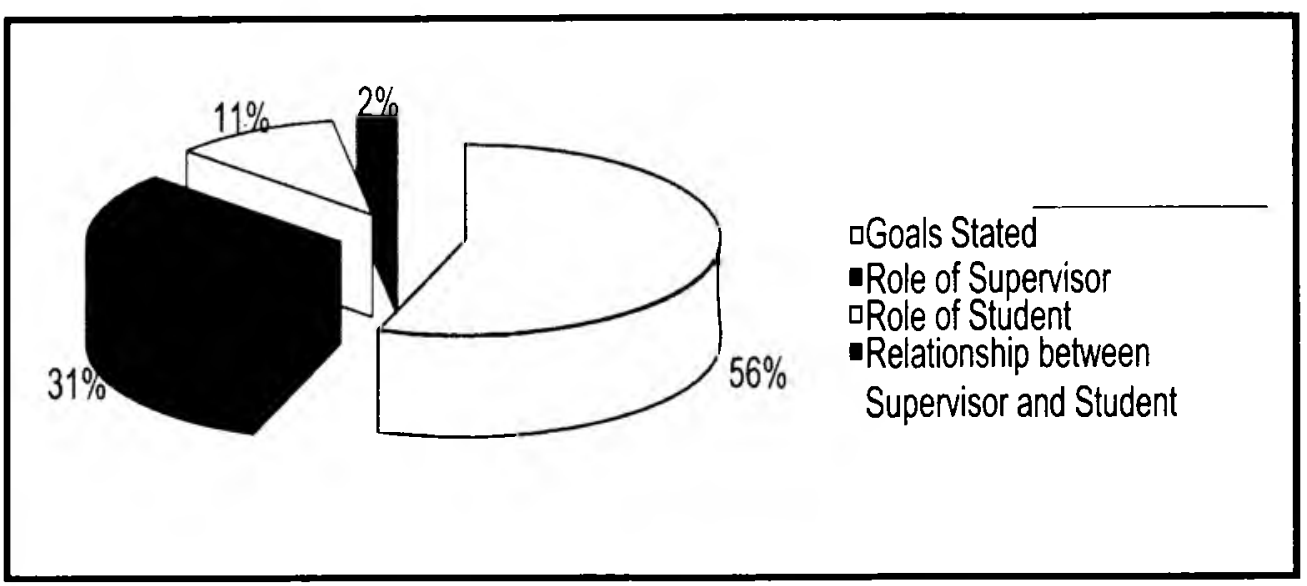

Figure 5. Length of Clinical Supervision Sessions

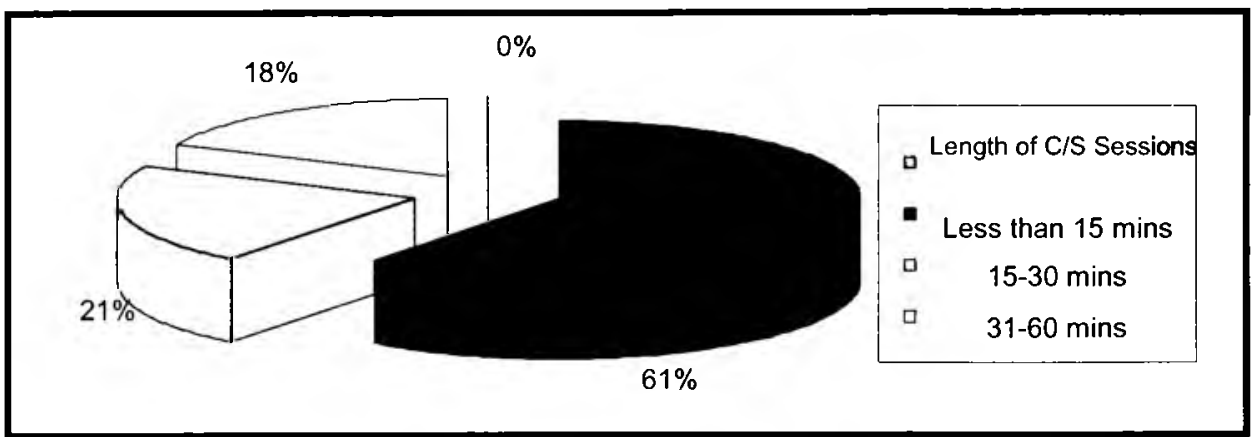

and expectations were discussed and 5\% the adequacy of clinical learning

Figure 6. Ward staff find clinical supervision time consuming

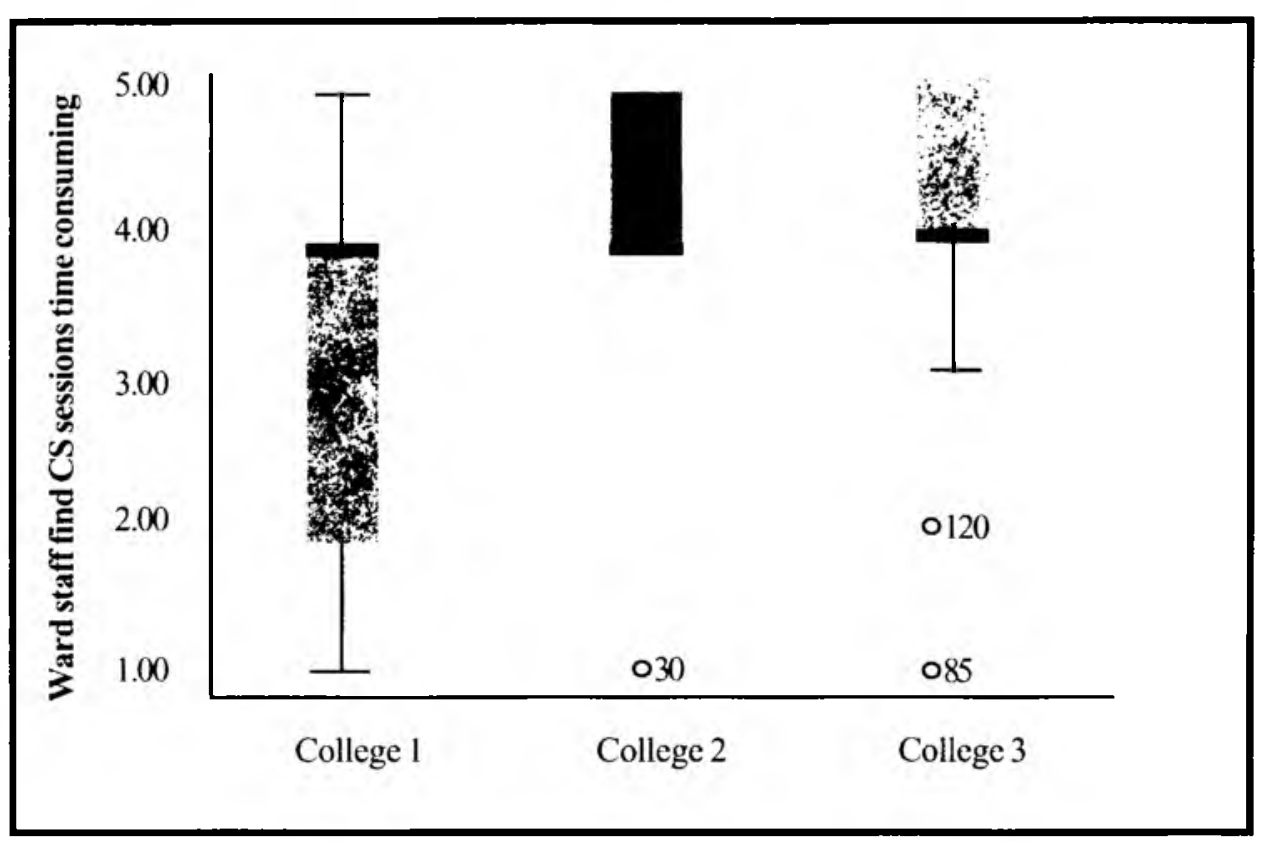

did not respond to this statement of the contract between student and supervisor. (Figure 3).

The conceptual framework used in the study indicates that the availability and experiences is one of the preconditions for successful supervision and learning. $56 \%$ (114) indicated that the goals of clinical supervision were stated, $31 \%(64)$ were informed of the role of the clinical supervisor, $11 \%$ (25) knew about the role

of the students and $2 \%$ (5) had knowledge of the relationship between the supervisor and the student (See Figure 3). These areas should form part of the contract that is between the clinical supervisor and the student and the two parties should be informed of the content of the contract, as indicated in the conceptual framework used in this study.

$13 \%(16)$ of the participants indicated that the clinical learning environment had adequate learning experiences while $80 \%$ (98) indicated that the experiences were not adequate. $7 \%$ of the participants pointed out some learning experiences were irrelevant. According to the conceptual framework used in this study inadequate and irrelevant learning experiences limit learners from developing required clinical competencies.

The conceptual framework used in this study indicates that the availability and adequacy of clinical learning experiences is one of the preconditions for successful clinical supervision and learning.

\section{Core of Clinical Supervision}

About $61 \%$ (71) of the respondents indicated that clinical sessions took less that 15 minutes, $21 \%$ (26) stated that the length of their clinical learning sessions ranged between 15 to 30 minutes and $18 \%(22)$ had clinical learning sessions which were above 30 minutes (Figure 5).

None of the respondents had clinical supervision sessions daily.

$49 \%(60)$ had sessions weekly and $51 \%(62)$ had sessions fortnightly. $96 \%$ of the participants had a copy of learning objectives, and 3\% reported that they did not have a copy. $2 \%$ of the participants did not respond to this question.

Responding to the statement about the support in the unit, $66 \%(80)$ got support from peers, 32\% (39) got support from the unit staff, and no participants had support from the hospital coordinator, $3 \%$ did not respond to this statement.

According to the graph (Figure 6) college 1 responses were significantly lower (tended to disagree more) than the 
responses from the other colleges in response to the statement that ward staff find clinical supervision time consuming.

\section{Comparison of critical incidents between the three hospitals}

The highest proportion of incidents was reported in College 1 , followed by College 2 and the lowest in College 3. Overall $21.2 \%(n=25)$ of respondents reported critical incidents. Of the 25 participants who reported critical incidents, $68.2 \%$ received support. There was no difference in the proportion receiving support by hospital. Thus similar proportions of participants who reported incidents received support in the three hospitals.

\section{Critical incidents}

Critical incidences were also analysed qualitatively. Critical incidences are a set of procedures used for collecting direct observations of human behaviour that have critical significance. A critical incident can be described as one that makes a significant contribution, either positively or negatively. (http:// wikipedia.org/wiki/critical incident technique 16/09/08)

Two themes, academic support and emotional support emerged out of the critical incidents.

\section{Academic support}

One student reported that the ward was grossly short staffed and that she was allocated to care for a patient with a tracheotomy. This task was allocated to her because it was assumed that as an old student, she would have been exposed to such a procedure, but, unfortunately for her, it was her first time. The student felt uncomfortable reporting this to the unit manager, but the unit manager noticed that this student had a problem, and made time available to teach the student.

The unit manager was very supportive. She demonstrated to me the procedure, starting from the setting of the tracheotomy tray, to the procedure of caring for a tracheotomy.

According to Lyth(2000) the supportive and restorative outcome of clinical have been decreased anxiety and decreased stress.

Some of the participants however reported that they did not receive academic support because they were regarded as a burden by the unit staff. Sometimes the unit were grossly short staffed and they were expected to function independently even when they required some guidance. The unit staffs' attitude towards them when they requested to be taught something was very negative. They were regarded as old nurses with experience, neglecting the fact that they were being trained or prepared to be a different category of nurse (registered nurse). They had never functioned as registered nurses before. Whatever they had learned was mainly in service as enrolled nurses.

Sometimes we were highly stressed to complete our tasks before the end of the year. We were overworked and not given enough time to learn. As a result we found ourselves behind compared to other students.

According to Morton Cooper Palmer (2000) the role of the supervisor is described as supportive in accomplishing a task, assessing and solving work related problems with the student and assessing the skills and knowledge of individual students.

The participants reported that they were treated differently as opposed to four year comprehensive students. These nurses received more support than they did. Time was made available for such students to attend teaching sessions, whereas in most cases it was assumed that old students knew most of what was taught in the ward and therefore should continue with their work. They were not given an opportunity to choose whether to attend the sessions or not. Sometimes, due to staff shortages, they were used as part of the workforce because of their experience, bypassing the reason for their presence in the units, namely to learn what would be expected from them as registered nurses.. One of the participants reported that being regarded as part of the workforce delayed her in completing her objectives in particular units.

I wanted to attend a demonstration as was expected according to my workbook, but the sister who was leading our team just said no, because there was no one to continue with my tasks. She did, however, allow the four-year course student to attend.

\section{Emotional support}

Some of the participants, although only a few, pointed out that in critical incidences they did receive some form of support. There were times where the unit staff ensured that they received support even from other professionals.

One of the participants reported the death of a baby due to the unavailability of doctors in private institutions. The student blamed herself for not doing enough. The student received support from the ward staff and was sent for counselling I was blaming myself because we lost a baby in the unit. I was the only one in the unit. The sister and other staff members were on a tea break and the other staff member was busy with the errands. The critically ill child suddenly turned blue and required resuscitation. The doctor was not available. In private hospitals, getting a doctor for resuscitation takes time, and there was no readily available team for resuscitation. I called for help, but the response was poor and we lost that baby. I could not take what happened, but the ward staff went out of their way to support and counsel me. I was even referred to the psychologist for help. According to White et al (1998) outcomes such as professional support and gaining support for work related problems are developed during clinical supervision. Some of the participants received emotional support especially when dealing with difficult patients. It emerged from the findings that some of the patients undermined students and only respected qualified nurses. About three of the participants reported that they were physically assaulted by patients who undermined them, but who changed their behaviour when the qualified nurses attended to them. In two of these incidences the unit staff supported the students and intervened. One of the participants was bitten by a patient on the arm. She was counselled and the procedure of needle stick injury was followed and she was started on Antiretro-viral drugs. In one of the incidences, it was as if the student invited the assault. Instead of being supported, she was made to complete a statement independently with no one guiding her through the process. She was humiliated by the patients in front of the patients and unit staff, and was also humiliated by the unit manager who shouted at her in front of all these people and ordered her to write a statement, instead of attending to her as she had been assaulted by the patient:

I once worked in a unit where a sister was not sympathetic to our needs as students. I was pregnant and I started to 
bleed while I was at work. When reporting my problem to the sister she ignored me instead of allowing me to go and seek medical assistance. I was made to continue with my work. After some time I decided to phone my clinical instructor and report to her because the problem was getting worse. She then intervened, and that is when I was allowed to attend to my problem.

White et al (1998) emphasises that clinical supervision is a form of employee mental health care or preventative mental health welfare and a part of occupational safety. From the participants' critical incidences it also became evident that the emotional support they received was very limited, especially from the unit managers. They were mainly expected to work, even when they had social or health problems. The unit managers' concerns were the coverage of the ward hospitals.

\section{Discussion of Findings}

The majority of the respondents acknowledged the need for clinical supervision. The students found clinical supervision useful in promoting working practices and in facilitating their professional development. It is difficult to establish supervision without the dedicated support of the clinical supervisor. It takes great energy to keep the groups focused and committed in an environment where there are continuous high patient workloads and frequent shortages of staff.

\section{Preconditions or Antecedents for clinical supervision}

The findings in this study revealed that other institutions lacked trained staff to carry out supervision. They used clinical supervisors without a nursing education qualification which is not in line with the South African Nursing Council's expectations. Lack of trained staff was one of the difficulties of clinical supervision which was pointed out by Thomas and Reid (1995:883-885). It emerged in this study that the time available was insufficient for clinical supervision, and the opportunities for reflection were limited due to busy wards. Some of the clinical staff was not in favour of releasing students to attend clinical supervision sessions because students served as an extra pair of hands. The bridging programme students were still regarded as part of the unit staff, and releasing them for clinical supervision sessions meant that some activities would not be performed. The findings revealed that there was a large age gap between the clinical supervisors and the students and that all clinical supervisors were females. . It was not easy to establish why certain institutions used unqualified nurses, but according to Thomas and Reid (1995p883-885) untrained staff in their study was used as a result of a lack of trained staff. The researcher was unable to establish from participants whether those who possessed a nursing education qualification were prepared academically for this role. This answer would have been answered if nurse educators were included in this study. From the researcher's experience, the training and education of nurse educators does not go in-depth with clinical supervision. Only the basics of clinical supervision are discussed.

\section{Core of clinical supervision}

The first session of clinical supervision was used to explain the goals of clinical supervisions, the expectations, roles and responsibilities of each party (clinical supervisor and student).

The participants reported that they had individual as well as group clinical supervision sessions, and most of the participants, $(71 \%)$ reported that sessions lasted less than 15 minutes. Relatively few participants $(29 \%)$ received clinical supervision that was longer than 30 minutes. This suggests that less time was allocated to clinical supervision. According to the framework which was used in this study adequate time should be allocated to clinical supervision sessions, because clinical supervision facilitates the development of students as professionals. The participants pointed out that more time should be dedicated to clinical teaching and learning, they should have more frequent sessions, and should not be regarded as part of the workforce but as students first, then secondly as part of the clinical staff. This supports the findings in the study by Winstanley and Edward (2003:6) that longer sessions and more frequent sessions may be more effective.

The findings showed that most ward staff in the three hospitals found it difficult to find time for clinical supervision sessions as it was time consuming. This is supported by Davhana-Maselesesle (2000:126) in her study on problems with integrating theory and practice in selected clinical nursing situations that due to the lack of time and knowledge of practical skills as well as lack of confidence, tutors and ward staff are not fully involved in clinical supervision .

\section{Outcomes of clinical supervision}

The purpose of clinical supervision emerged as being to promote academic, personal and professional growth in the students. Although this was not supported in some units, there were units which supported this aim. This was in line with the developmental model which was described by Leddick (1994:10-24) as having three developmental phases with the student moving towards competence, self-assurance and self reliance. To facilitate growth, each student had a copy of objectives to be covered in the clinical settings, but the participants raised the concern that they were unable to cover all the objectives on time because they were overloaded with work in the units, and were not regarded as students. They did not have enough time to develop themselves towards becoming professional nurses. They were still treated as staff nurses who were part of the work team.

The formative aspect (educative) of clinical supervision was more pronounced compared to restorative and normative aspects. According to the findings in this study, clinical supervisors focused more on facilitating the development of technical skills instead of facilitating the development of competencies (knowledge, attitude and skills), and the ability to reflect. The aspect of promoting guided reflection did not come out clearly in this study.

It was found that most ward staff and students become motivated during clinical supervision sessions, despite the fact that the clinical supervisor may discuss sensitive issues that have been encountered during clinical supervision sessions.

The critical incident analysis revealed that supervised nurses continued to use informal support as well as their supervision sessions to discuss clinical issues.

How clinical supervision emerged in this study was in line with how Winstanley and Edward (2003:3) view clinical supervision. These authors however also add that clinical supervision enables individuals to develop competence and 
assume responsibility for their own practice and to enhance consumer protection and safety in complex situation. Enhancing patient safety emerged when participants were reflecting on critical incidences. In some situations where participants were not skilled, or not familiar with a procedure to be performed, the clinical staff made themselves available to help the participants and to protect the patients.

\section{Recommendations}

Recommendations will be discussed under three headings, namely Preconditions or Antecedents for Clinical Supervision, Teaching Learning Process and Support.

\section{Preconditions or Antecedent}

- The planning of supervision activities should have in mind the identification of resources and the necessary time for this function to take place. Initial training for the clinical instructors and ward staff should be made available to maintain the quality of clinical supervision that is provided..

- $\quad$ Regular updates in training are necessary considering the fact that healthcare is provided in a mixed economy with diverse systems, in which the fragmentation of the nursing profession is escalating. In the midst of all this fragmentation, the issue for the individual will be more about creating a professional and psychological secure base, within which to receive support and understanding, and to reflect in depth on the quality of care provided by clinical supervision

- A structured learning contract with agreed learning outcomes between the student and the supervisor.

\section{Teaching Learning Process}

- $\quad$ The partnership between educational staff and clinical staff is extremely useful as it helps to keep a balance between theory and practice and encourage educators and supervisors to reflect on what they are doing educationally and why.

Preparation of nurse educators for their clinical supervision role is vital. This will include an indepth understanding of clinical supervision and teaching, starting from the planning phase of curriculum development, identifying appropriate clinical facilities, negotiating a working partnership with the clinical setting, planning for the actual process of clinical supervision. how to conduct clinical supervision and to evaluate the expected outcomes of clinical supervision

\section{Support}

- $\quad$ An open, effective and supportive relationship based on mutual trust and respect from both management, student and supervisor needs to be developed to support bridging programme students and this should be maintained at all time throughout the training.

The introduction of peer supervision could be effected through the placement of a junior student with a senior student. It would be beneficial for the student who is in the second year of training and the first year student to form a supportive relationship which would aid the development of both parties. The way in which peer support system is organized will vary according to the needs of individual students' abilities, needs and local environment.

\section{Conclusion}

From the above discussion and based on the findings of the study, it has been established that clinical supervision sessions are vital for the development of clinical skills amongst the bridging programme students however time resources and ideological differences are issues that may impede progress. It has also been found that there is a need for mutual support between ward staff and supervisors, as well as among the students themselves. Integral to the concept of clinical supervision is the notion that the patient must be the focus of the exercise. The positive outcomes of clinical supervision are that there is reduced professional isolation, professional development, improved quality care, reduced clinical risks, improved colleague support, problemsolving, better-informed staff and improved teamwork. Effective clinical supervision has to be encouraged and supported. It requires enthusiasm and commitment from students and those involved in clinical supervision.

\section{References}

ANDREWS, M \& ROBERTS, D 2003: Supporting student nurses learning in and through clinical practice: the role of the clinical guide. Nurse Education Today, 23(7): pp474-481.

BENOLIEL, JQ 1988: Some Reflections on Learning and Teaching In Journal of Nursing Education. 27(8): pp340-341.

BJORK, IT 1995: Neglected Conflicts in the Discipline of Nursing: Perception of the Importance and the Value of Practical Skill In Journal of Advanced Nursing. 22 (1): pp 6-12.

BURNS, N \& GROVE, SK 2001: The practice of nursing research : conduct/ critique and utilization. Philadelphia: Saunders.

CLARK, P; JAMIESON, A; LAUNER, J; TROMPETAS, A; WHITEMAN, J \& WILLIAMSON, D 2006: Intending to be a supervisor, mentor or coach: Do you know which, what for and why? Education for Primary Care. 17:pp 106-116

DAVHANA-MASELESELE, $M$ 2000: Problems in integrating theory with practice in selected clinical nursing situations. Master's dissertation. Pretoria: University of South Africa.

LITA, H; ALBERTS, U; VAN DYK, \& SMALL, LS 2002: Factors that influence the selection of learning opportunities for student nurses in primary health care. Health SA Gesondheid. 7(2):pp25-34

LIPINGE, SN \& VENTER, ES 2003: Student nurses experiences during a rural community placement programme in Nambia. Curationis 26(4):pp5-12

ELKAN, R \& ROBINSON, J 1993: Project 2000: The Gap Between Theory 
and Practice. In Nurse Education Today. 13(4): pp295-298.

HENDERSON, S 1995: Clinical Teaching Involves more than Evaluating Students. In Summers, L (ed), A Focus on Learning. pp 121-125. Proceedings of the $4^{\text {th }}$ Annual Teaching Learning Forum, Edith Cowan University, February 1995. Perth: Edith Cowan University

HINTZE, J 2001:Post hoc KruskalWallis Multiple Comparison $Z$ value tests Number Cruncher Statistical Systems (NCSS) and Power Analysis and Sample Size (PASS). Kaysville Utah

HUMPHREYS, A; GIDMAN, J \& ANDREWS, $M$ 2000: The nature and purpose of the role of the nurse lecturer in practice settings. Nurse Education Today, 20, pp311-317.

HYRKAS, K 2002: Clinical Supervision and Quality Care. (Academic Dissertation).Tampere Tampereen Yliopistopaino Oy Juvenes Print.

IRBY, DM 2004: "Clinical Teacher Effectiveness in Medicine" In J. Med. Educ. 53.pp808-815

JINKS, A\& PATEMAN, B 1998: Neither this nor that: The Stigma of Being an Undergraduate Nurse. In Nursing Times, 2(2): pp.12-13.

JOWET, SJ; WALTON, I \& PAYNE, S 1992: The Introduction of Proiect 2000Early Perspectives from the Students. Interim Paper No. 5. Slough: National Foundation for Educational Research.

KEMPPAINEN, JK 2001: The critical incident technique and nursing care quality research . In Journal of Advanced Nursing. 32(5): pp 1264-1272.

LEDDICK, GR 1994: ED372340 94 Models of Clinical Supervision. In ERIC Digest. Greensboro, NC: ERIC Clearinghouse on Counselling and Student Services._Mendoza DW

LYTH, G.M. 2000: "Clinical Supervision, a Concept Analysis" In Journal of Advanced Nursing. 31(3):pp 722-729.

MOELLER, P 1984: Clinical supervision: Guidelines for managing the problem student. Journal of Allied Health. 8, 205 211
MOETI, MR; VAN NIEKERK,SE \&VAN

VELDEN, CE 2004: Perceptions of the clinical competence of newly registered nurses in the North West Province. Curationis 27(3):pp72-84

MOGAN,J \& KNOX,JE 1997: Characteristics of Best and Worst Clinical Teachers as Perceived by University Nursing Faculty and Students. In Journal of Advanced Nursing. 12: pp331-337.

\section{MORTON-COOPER,A \& PALMER,A}

2000: Mentoring, Preceptorship, Clinical Supervision.Blackwell Science,Oxford, UK

MTHEMBU, SZ 2003: Analysis of the assessment of clinical leaming in selected nursing education institutions in KwaZulu-Natal with an outcomes-based education (OBE) context. Unpublished thesis. University of KwaZulu-Natal, Durban: South Africa.

PROCTOR, B 2001: Training for the supervision alliance: attitude, skills and intentions. In: Cutliffe J., Butterworth T. and Proctor B. (eds). Fundamental Themes in Clinical Supervision. Routledge: London.

QUINN, FM 2000: Principles and Practice of nurse education. $4^{\text {th }}$ edition. University of Greenwich London: Stanley Thornes Publishers.

SMITH , G 2000: Friendship with Clinical Supervision: A Model for the NHS.

Online:Hptt://www. clinical supervision. com.

SOUTH AFRICAN NURSING COUNCIL 1995: R683 Guidelines for Bridging for Enrolled Nurses Leading to Registration as a General or a Psychiatric Nurse. Pretoria: SANC

TIWARI,A; LAM, D; YUEN, KH; CHAN, R; FUNG, T \& CHAN, S 2005: Student learning in clinical nursing education: Perceptions of the relationship between assessment and learning. Nurse Education Today.25.(4), pp299-308.

THOMAS, B \& REID, J 1995: "Multidisciplinary Clinical Supervision" In British Journal of Nursing. 4(15):pp. 883-885.

WHITE, E; BUTTERWORTH, T;
BISHOP,V; CARSON, J; JEACOCK, J \& CLEMENTS, A 1998: Clinical supervision: insiders report of a private world. JAdv Nurs 28:pp 185-192.

WONG, J \& WONG, S 1987: Towards effective clinical teaching, Journal of Advanced Nursing 12(4):pp505-513.

WINSTANLEY, J \& EDWARD, W 2003: Clinical Supervision Models, Measures and Best Practice. In A Nurse Researcher. 13515578, Vol. 10, issue 4. 